ISSN 1991- 8690

Website: http://jsci.utq.edu.iq

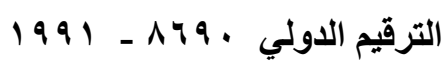

Email: utjsci@utq.edu.iq

\title{
Effect of the Crosslinking Between the Asphalt and Polyethylene on the Viscoelastic Properties of Polyethylene Melt Extruding Through Capillary
}

\author{
Moayad N. Khalaf ${ }^{(1)}$ \\ Hashmya Abd-Alkarem ${ }^{(3)}$
}

Mostafa M. Naeem ${ }^{(2)}$

Mazen Abd-Alhasan ${ }^{(4)}$

1- Chemistry Department, College of Science, Basrah University, Basrah-iraq..

2- Ministry of Oil, South Oil Comanay, Basrah-Iraq.

3- State Company of Petrochemical Industry, Basrah-Iraq

4- College of Engineering, Basrah University, Basrah-Iraq.

\begin{abstract}
$\underline{\text { Abstract }}$
The viscoelastic properties of polyethylene were studied with different percent of asphalt $(1 \%, 3 \%, 5 \%, 7 \%$ and $10 \%)$ and $1 \%$ of organic peroxide as crosslinking agent. The data shows that the $1 \%$ of asphalt loading in the polymer decrease the shear stress and viscosity of the matrix polymer in all the test temperature $\left(170,190,210\right.$ and $\left.230^{\circ} \mathrm{C}\right)$. The best percent of asphalt that gives controlled crosslinking between the polymer chains was $1 \%$ asphalt loading, while higher asphalt percent will increase the chain entanglements .

$$
\begin{aligned}
& \text { الخلاصة }
\end{aligned}
$$

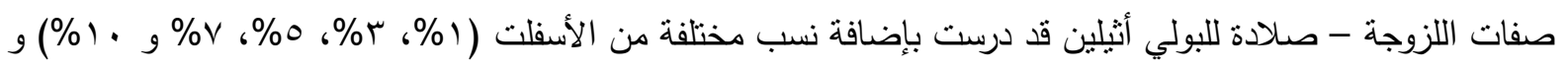

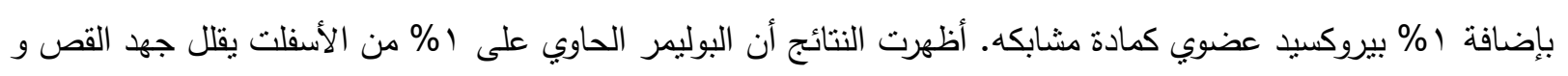

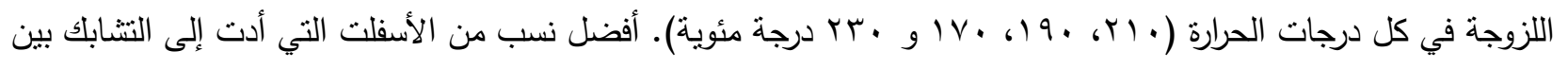

$$
\begin{aligned}
& \text { سلاسل البوليمر هي نسبة (\%)، بينما النسب الأعلى زادت من نسبة المعقد بين سلاسل البوليمر. }
\end{aligned}
$$




\section{$\underline{\text { Introduction }}$}

Many fabrication process for polymeric objects include melt extrusion in which the molten polymer is conveyed by a ram or a screw and the melt is then forced through a shaping die in continuous processing or into a mold for the manufacture of discrete molded parts $^{(1)}$. Most commercial polymers have high molecular weight ,their chain was highly entangled for that the flow properties of these polymer differ from the low molecular weight polymer. Viscosity is an important characterizing the flow of polymer fluids ${ }^{(2)}$.The factors affecting the viscosity were shear stress, shear rate, temperature, pressure and molecular chain structure.Crosslinking between the polymer chain and with other materials contain functional groups $^{(3-6)}$ will effect the molecular chain structure and effect the chain entanglements. In this work we study the effect of asphalt percent $(0,1,3,5,7$, and $10 \%$ ) and $1 \%$ organic peroxide on the shear stress and viscosity of low density polyethylene 463 at different shear arte and different temperatures .

\section{Experimental}

\section{Materials}

asphalt supplied from Basrah refinery with the following specifications.

\begin{tabular}{|c|c|}
\hline PROPERTY & VALUE \\
\hline Specific gravity at $15.6^{\circ} \mathrm{C}$ & 1.04 \\
\hline Flash point ${ }^{\circ} \mathrm{C}$ min. & 240 \\
\hline Penetration at $25^{\circ} \mathrm{C}(100 \mathrm{gm}, 5 \mathrm{sec}, 0.1 \mathrm{~mm})$ & $40-50$ \\
\hline Softening point ${ }^{\circ} \mathrm{C}$ & $49-58$ \\
\hline Ductility at $25^{\circ} \mathrm{C}$ min. $(\mathrm{cm})$ & 100 \\
\hline Solubility in $\mathrm{CCl} 4 \% \mathrm{w}$ min. & 99 \\
\hline Loss on heating $\% \mathrm{w}$ max $\left(5 \mathrm{~h}, 163^{\circ} \mathrm{C}\right)$ & 0.5 \\
\hline
\end{tabular}

min.: minimum, max. : Maximum

Low density polyethylene was supplied by SCPI (state company of petrochemical Industry), Basrah - Iraq with $\quad(\mathrm{MI}=0.38 \quad \mathrm{~g} / 10 \mathrm{~min}$. and

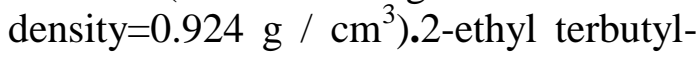
hexanoate peroxide $\left(\mathrm{C}_{67}\right)$ was supplied by Pergon g.m.b.h company with peroxide content $(98 \%)$.

\section{Instrument}

1- Capillary rheometer (Instron Model 3211).the capillary die $(D=1.257$ $\mathrm{mm}, \mathrm{L} / \mathrm{D}=80$ )and the piston speeds $(\mathrm{V})$ were $0.02,0.06,2.00,6.00$ and 20.00 $\mathrm{cm} / \mathrm{min}$. The relationship between shear rate $\left(\gamma_{w}\right)$ and $\mathrm{V}$ expressed as follows:

$$
\gamma_{w}=\frac{2}{15} V_{X H} \frac{D_{b}^{2}}{D_{c}^{3}}
$$

where $D_{b}$ and $D_{c}$ is the diameter of the cylinder and capillary diameter.

The wall shear stress was calculated using the following equations: ${ }^{(7)}$ 
Wall shear stress $\left(\square_{\mathrm{w}}\right)=\frac{\Delta P}{4 L} \times D_{b}$

Where $\square \mathrm{P}=$ pressure applied along the capillary, $\mathrm{D}_{\mathrm{b}}=$ diameter of the cylinder and $\mathrm{L}=$ length of the capillary .

The apparent viscosity $\left(\eta_{a}\right)$ was calculated from the equation :

$$
\eta_{a}=\frac{\tau_{w}}{\gamma_{w}}
$$

\section{Results and discussion}

Plot of apparent shear stress versus shear rate( flow curve) of the composite PE/asphalt ( different loading percent ) with $1 \%$ peroxide as crosslinking agent was shown in Fig.1.It is seen that the shear stress increased with an increase of shear rate. At low value of shear rate (velocity) ( 2.74,9.15 and $27.41 / \mathrm{S})$ the pure polyethylene with $1 \%$ peroxide have the lower values of shear stress ,this can be attributed to the low speed of test which gives the chain suffient time to arrange with the direction of flow. With increasing the value of shear rate the pure polyethylene shear stress was higher than the other asphalt loading and the lower value of shear stress was for $1 \%$ asphalt loading. We expected that the crosslinking between the asphalt functional groups and polyethylene chain at $1 \%$ asphalt loading gives the better control .

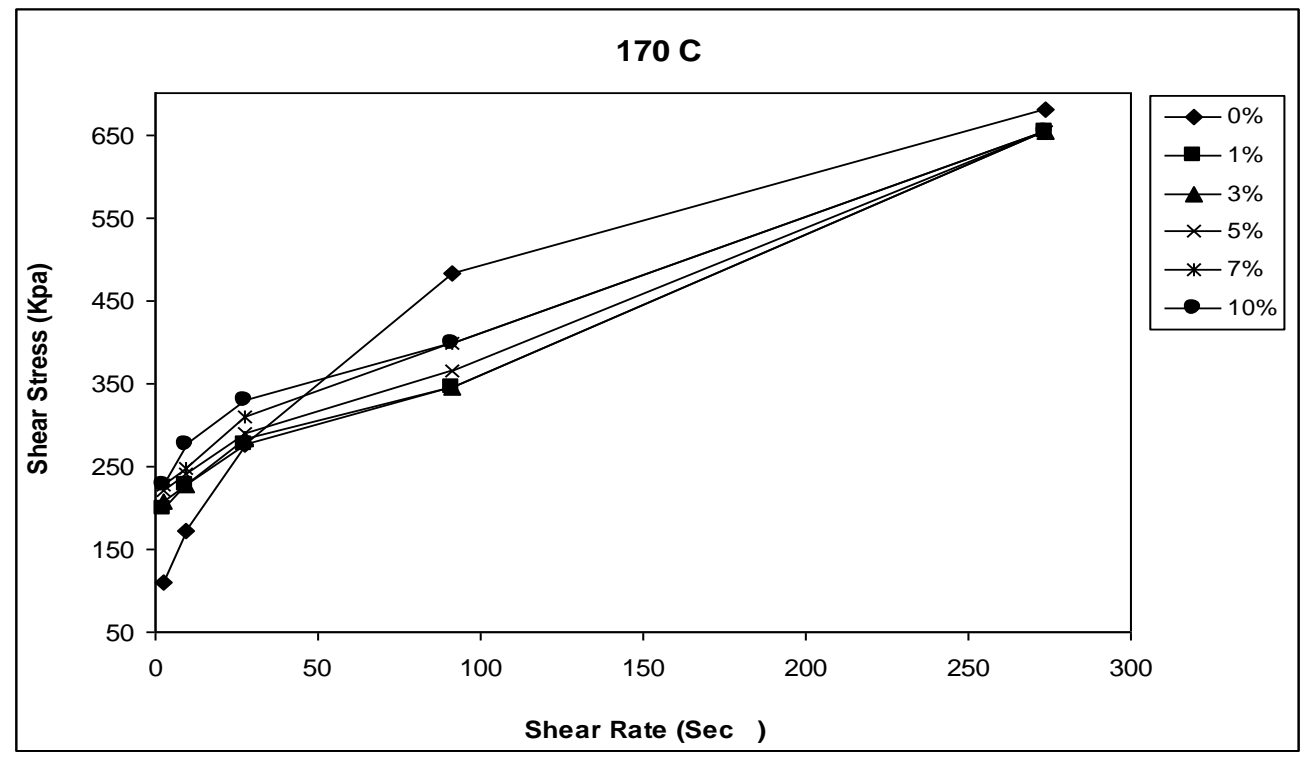

Fig.1. Relationship between apparent shear stress and shear rate for PE/asphalt and $1 \%$ peroxide at $170{ }^{\circ} \mathrm{C}$.

arrangement of the chain and exhibited the highest flow curve. At higher temperature of test $\left(190,210\right.$ and $\left.230{ }^{\circ} \mathrm{C}\right)$, Fig.2,3 and 4 the percent of crosslinking increase between the polyethylene chains with the asphalt functional groups, which causes highly chain entanglements and the flow of polymer was restricted and the shear stress increase with the $1 \%$ asphalt loading remain with less shear stress value compared with the other percent of asphalt loading 


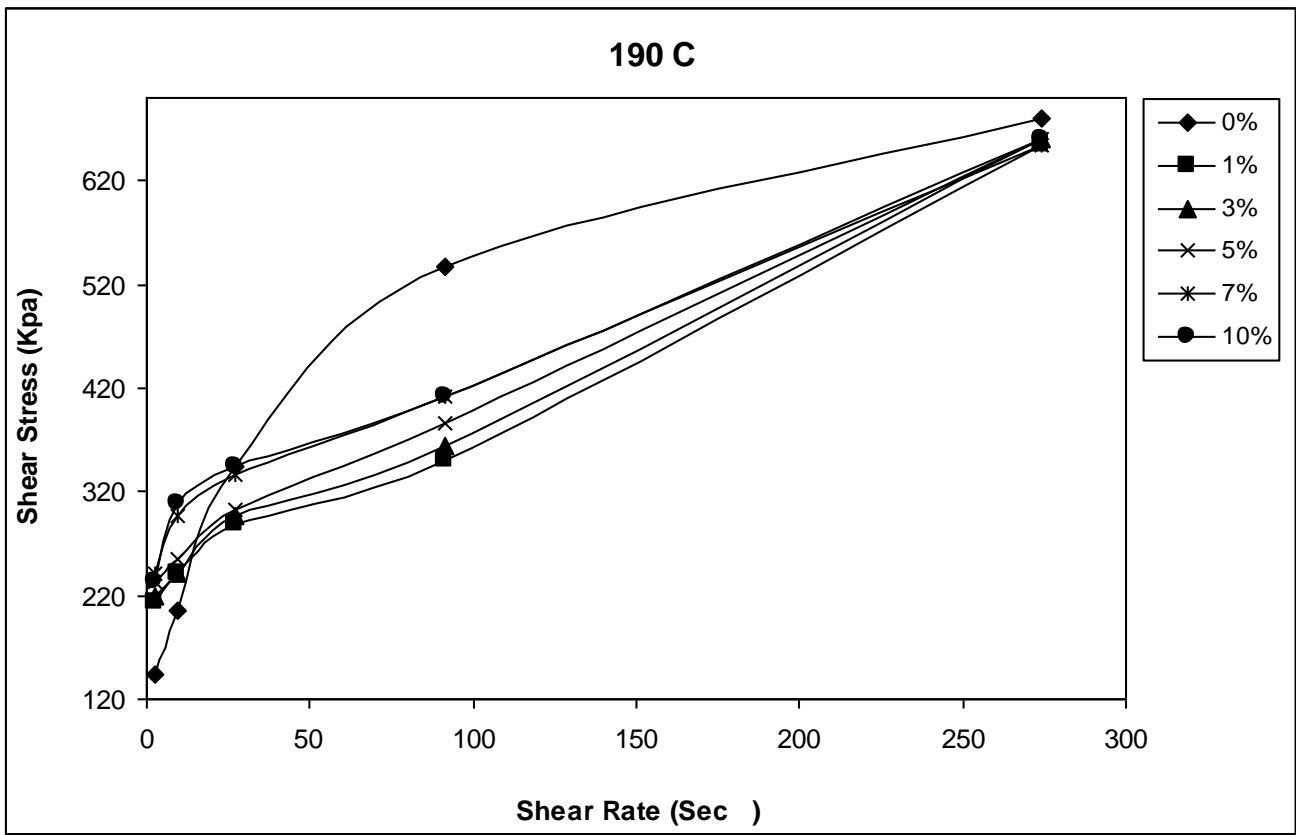

Fig. ${ }^{r}$. Relationship between apparent shear stress and shear rate for PE/asphalt and $1 \%$ peroxide at $190{ }^{\circ} \mathrm{C}$

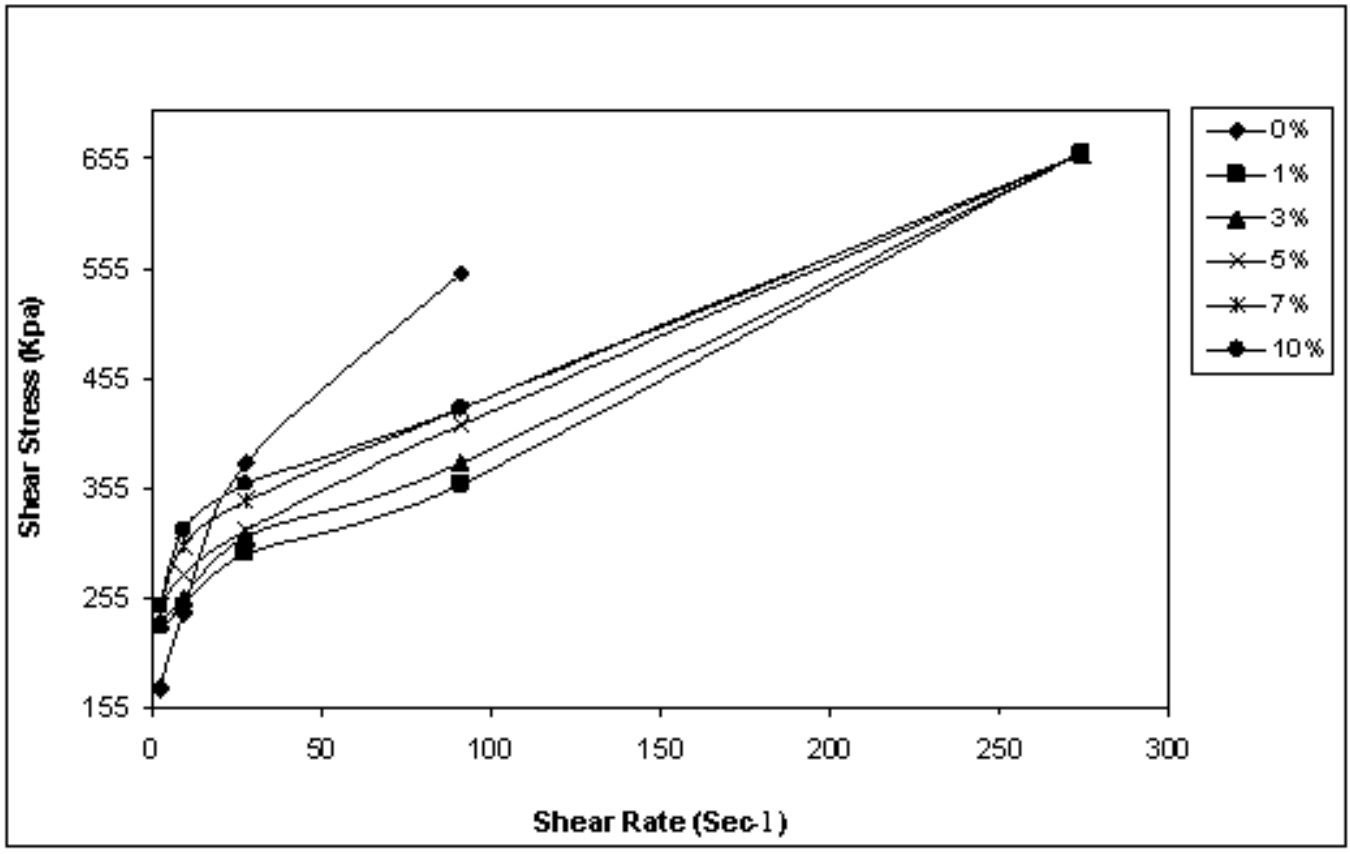

Fig. ${ }^{\Upsilon}$. Relationship between apparent shear stress and shear rate for PE/asphalt and $1 \%$ peroxide at $210{ }^{\circ} \mathrm{C}$ 


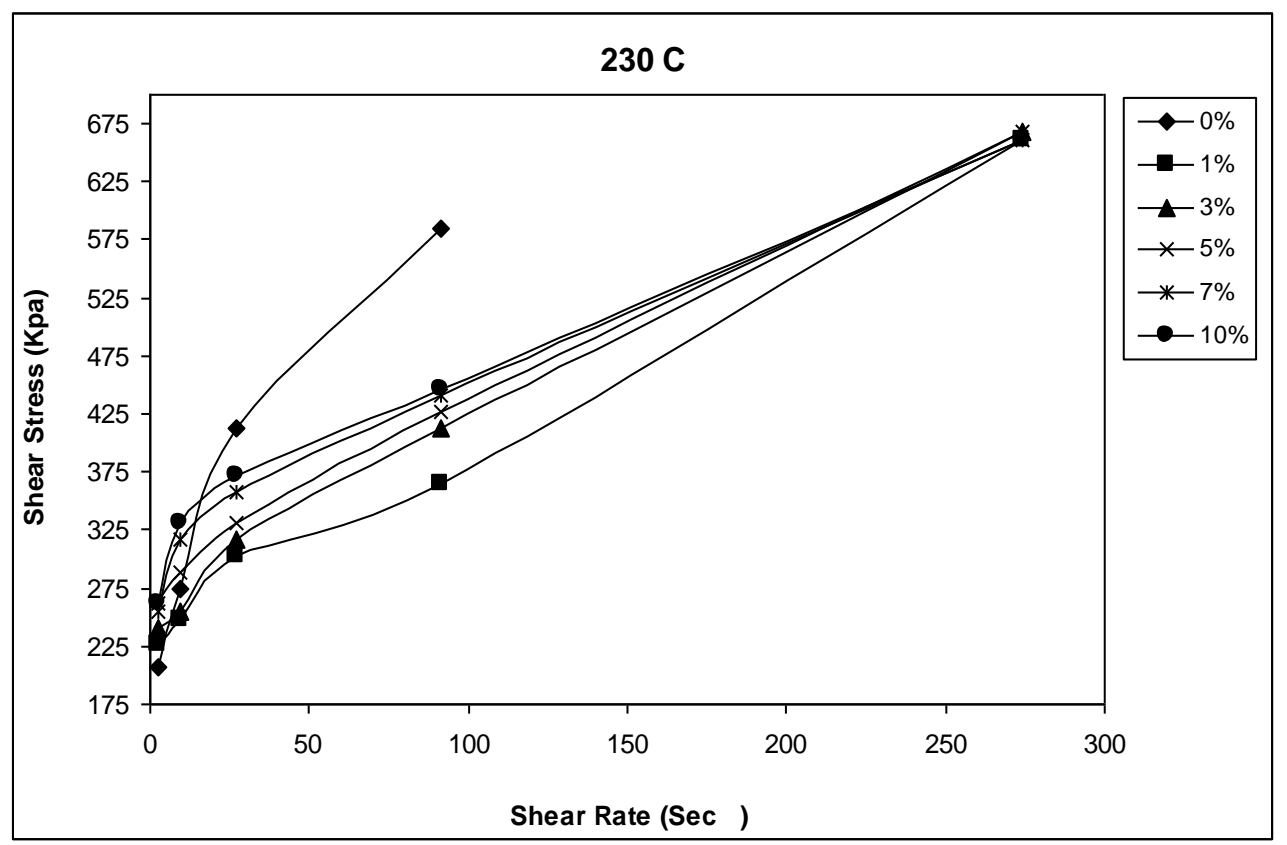

Fig.4. Relationship between apparent shear stress and shear rate for $\mathrm{PE} /$ asphalt and $1 \%$ peroxide at $230{ }^{\circ} \mathrm{C}$

the relationship between the apparent shear viscosity and shear rate of the composite from PE/asphalt ( different loading percent ) with $1 \%$ peroxide as crosslinking agent was shown in table 1 . We observed a decreasing in the value of shear viscosity with an increasing in shear rate. Therefore, for all the polyethylene melt exhibited shear thinning behavior that is the polymer was pseudopalstic ${ }^{(8)}$. at a given apparent shear rate, the apparent shear viscosity increased with increasing the temperature. The pure polyethylene with $1 \%$ peroxide show lower value of apparent shear viscosity at lower value of shear rate depending on the temperature, while the $1 \%$ percent of asphalt loading and $1 \%$ peroxide have the lower value of apparent shear viscosity. We contribute this behaviors to the appropriate crosslinking that reduce the resistance of the polyethylene to flow. 
Table 1: Shows the relationship between apparent shear viscosity and shear rate

\begin{tabular}{|c|c|c|c|c|c|c|c|c|c|c|c|c|}
\hline \multicolumn{13}{|c|}{ VISCOSITY (KPA/S) } \\
\hline & & $0 \%$ & & & & \begin{tabular}{|l|}
$1 \%$ \\
\end{tabular} & & & & $3 \%$ & & \\
\hline $\operatorname{Sh} \cdot \operatorname{Ra}\left(\mathrm{S}^{-1}\right)$ & \multicolumn{12}{|c|}{ Temperature $\left({ }^{\circ} \mathrm{C}\right)$} \\
\hline & 170 & 190 & 210 & 230 & 170 & 190 & 210 & 230 & 170 & 190 & 210 & 230 \\
\hline 2.74 & 40.17 & 52.72 & 62.77 & 75.32 & 72.81 & 77.83 & 82.86 & 82.86 & 75.32 & 80.35 & 85.37 & 87.88 \\
\hline 9.15 & 18.79 & 22.55 & 26.31 & 30.07 & 24.81 & 26.31 & 27.06 & 27.06 & 24.81 & 26.31 & 27.82 & 27.82 \\
\hline 27.4 & 10.04 & 12.55 & 13.81 & 15.06 & 10.04 & 10.54 & 10.79 & 11.04 & 10.29 & 10.79 & 11.29 & 11.55 \\
\hline 91.5 & 5.26 & 5.86 & 6.01 & 6.39 & 3.75 & 3.83 & 390 & 3.98 & 3.75 & 3.98 & 4.13 & 4.51 \\
\hline \multirow[t]{2}{*}{274} & 2.48 & 2.48 & & & 2.38 & 2.38 & 2.41 & 2.41 & 2.38 & 2.41 & 2.41 & 2.43 \\
\hline & & $5 \%$ & & & & $7 \%$ & & & & $10 \%$ & & \\
\hline 2.74 & 80.35 & 85.37 & 90.39 & 95.41 & 82.86 & 87.88 & 90.39 & 92.90 & 82.86 & 85.37 & 90.39 & 95.41 \\
\hline 9.15 & 26.31 & 27.82 & 30.07 & 31.58 & 27.06 & 32.33 & 33.08 & 34.58 & 30.07 & 33.83 & 34.58 & 36.09 \\
\hline 27.4 & 10.54 & 11.04 & 11.55 & 12.05 & 11.29 & 12.30 & 12.55 & 13.05 & 12.05 & 12.55 & 13.05 & 13.55 \\
\hline 91.5 & 3.98 & 4.21 & 4.51 & 4.66 & 4.36 & 4.51 & 4.66 & 4.81 & 4.36 & 4.51 & 4.66 & 4.88 \\
\hline 274 & 2.38 & 2.41 & 2.41 & 2.43 & 2.38 & 2.385 & 2.41 & 2.41 & 2.38 & 2.41 & 2.41 & 2.41 \\
\hline
\end{tabular}

\section{$\underline{\text { References }}$}

1- J-Z.Liang, Polymer Testing, 23, 441; (2004).

2- J-Z.Liang, Polymer, 42, 3709; (2001).

3- R. S. Lenk, Polymer Rheology, Applied Science Publishers LTD, LONDON, (1978).

4-Y.T. Sung, C.K. Kum, H.S. Lee, J.S. Kim, H.G. Yoon and W.N. Kim, Polymer, Volume 46, 25,11844 (2005).
5-M. H. M. Al-Soltan M.Sc. Thesis, Basrah University, Basrah, Iraq, (2002).

6-M. N. Khalaf, Ph.D Thesis, Basrah University, Iraq, (2005).

7-A. Teruo Morita, M. Shissun Toma and M.Aurelio De Paoli, Polymer Testing, 25, 197 (2006).

8-C.Nakson, S.Saiwari and A.Kaesaman, Polymer Testing 25,413;(2005). 